\title{
Living with chronic obstructive pulmonary disease in Lebanon: a phenomenological study
}

Rita Georges Nohra, ${ }^{1,2,3}$ Jean-Manuel Morvillers, ${ }^{1,4}$ Hala Sacre, ${ }^{5}$ Pascale Salameh ${ }^{5,6,7}$ and Monique Rothan-Tondeur ${ }^{1,8}$

${ }^{1}$ Université Sorbonne Paris Nord, Chaire Recherche Sciences Infirmières, Laboratoire Educations et Promotion de la santé, LEPS, Villetaneuse, France (Correspondence to: Rita Georges Nohra: ritag.nohra@gmail.com). ${ }^{2}$ Hôtel-Dieu de France Hospital, Beirut, Lebanon. ${ }^{3}$ Faculty of Public Health, Lebanese University, Fanar, Lebanon. ${ }^{4}$ Pôle PEPIT. GHU Paris Psychiatrie \& Neurosciences, Paris. ${ }^{5}$ Institut National de Santé Publique, Epidémiologie Clinique et Toxicologie - Liban (INSPECT-LB), Beirut, Lebanon ${ }^{6}$ Faculty of Pharmacy, Lebanese University, Hadat, Lebanon ${ }^{7}$ University of Nicosia Medical School, Nicosia, Cyprus ${ }^{8} \mathrm{AP}-\mathrm{HP}$, Chaire Recherche Sciences Infirmières, Paris, France

\begin{abstract}
Background: Lebanon has the fastest growing older adult population in the Arab region but few social resources to address their needs. No studies have explored the experience of patients with chronic obstructive pulmonary disease (COPD) in Lebanon.

Aims: Exploring the experiences of individuals living with COPD in Lebanon.

Method: Using a descriptive phenomenological research design, qualitative individual semi-structured interviews were conducted with COPD patients living in Lebanon, between May 2019 and September 2019.

Results: Fifty participants agreed to be interviewed. The majority were men (56\%) and had moderate COPD (40\%). Mean age was 71.5 (standard deviation 9.0) years. We found that COPD affects three dimensions of patients' lives: educational, organizational and psychosocial.

Conclusion: The results highlight the need for multidisciplinary strategies to address the needs of people with COPD in Lebanon, including their caregivers. Strategies include patient education and the development of new methods to facilitate and promote partnership between health care professionals, COPD patients and their caregivers.

Keywords: COPD, elderly, qualitative study, phenomenology, Lebanon,morbidity, mortality

Citation: Nohra RG; 1 Morvillers J-M; Sacre H; Salameh P; Rothan-Tondeur M. Living with chronic obstructive pulmonary disease in Lebanon: a phenomenological study. East Mediterr Health J. 2022;28(2):114-120. https://doi.org/10.26719/emhj.22.027

Received: 08/03/21; accepted: 15/06/21

Copyright $@$ C World Health Organization (WHO) 2022. Open Access. Some rights reserved. This work is available under the CC BY-NC-SA 3.o IGO license (https://creativecommons.org/licenses/by-nc-sa/3.o/igo).
\end{abstract}

\section{Introduction}

Chronic obstructive pulmonary disease (COPD) is one of the leading causes of morbidity and mortality worldwide. Studies estimate that by 2030 , COPD would be the fifth leading cause of death in high-income countries and the third leading cause of death in middle-income countries (1). Since 2016, research has shown that COPD is already established as the third leading cause of death in the world with about 3 million deaths and 251 million cases, $90 \%$ of which occurred in low- and middle-income countries (2) such as Lebanon.

The first, and so far only, national study to determine the prevalence of COPD in the adult Lebanese population revealed a prevalence of $9.7 \%$ according to the GOLD definition, of which $80 \%$ of cases in the smoking population are unrecognized and undiagnosed (3). Moreover, a study conducted in 10 countries in the Middle East and North Africa (MENA) region showed that in Lebanon, $71.8 \%$ of COPD patients were still smoking and only $30.6 \%$ were receiving respiratory treatment (4).

Complete recovery from COPD is currently not achievable, and as the disease progresses patients experience worsening breathing difficulty and disruption that affect their quality of life $(5,6)$. Therefore, COPD requires major changes in the daily lives of patients, who must adhere to treatment, change their lifestyle and monitor their signs and symptoms (7).

Essentially, COPD has been considered a condition of accelerated lung aging; consequently, the prevalence of COPD is three times higher in people over the age of 60 years (8). Lebanon has the fastest growing older adult population in the Arab region, but few social resources to address their needs (9). To date, no study has explored the experience of patients with COPD in Lebanon. Thus, the aim of our study was to describe the phenomenon of living with COPD from the Lebanese individuals' perspective.

\section{Methods}

\section{Design}

A descriptive phenomenological research design was used, which is anchored in Husserl's philosophical phenomenology, and developed and modified to be applicable as a scientific research method. The aim of phenomenology is to seek the essence of human phenomena as lived and experienced and present them and their meanings as faithfully as possible (10), free from preconceptions, beliefs and knowledge of the phenomenon. 
Throughout this study, we followed the Standards for Reporting Qualitative Research guidelines (11).

\section{Participants}

The participants were recruited from four university hospitals in Beirut. Eligibility criterion was clinical diagnosis by pulmonologists, and participation was voluntary. First, the study was explained to the pulmonologists, then 135 patients on the lists they provided were contacted and asked if they were willing to be interviewed at their homes. The inclusion criteria were COPD diagnosis with over 40 years old, and being able and willing to consent to and engage in the research study.

Creswell states that "up to a maximum of 10 interviews" is sufficient for phenomenological research (12). However, because the size of a sample depends on the complexity of a phenomenon (13) and in order to create a rich understanding of the phenomenon of living with COPD in Lebanon, we included all participants who agreed to take part in the study, therefore covering and thus a broad range of people using characteristics such as sex, age and economic situation.

\section{Data collection}

Face-to-face, semi-structured interviews were conducted by the principal investigator between May 2019 and September 2019 at the participants' homes. Interviews were systematically audio and video recorded after obtaining the participant's consent. An interview guide with open questions was developed in advance by the principal investigator and tested with one participant. The interviews were relatively open and partly influenced by the participant's concern. The investigator was well trained and careful to avoid leading questions. After some sociodemographic questions, the interview began with an opening question, "Tell me more about your experience with COPD". Next, a series of prompts were used inviting the participants to describe their experiences and their visions for the future. The investigator then summarized the exchange so that the patient could validate whether they were in agreement with what had been said during the interview. The participants were visited a second time to present the results. All participants agreed with the results.

\section{Data analysis}

Analysis of the results started immediately after the interviews. The audio and video recordings were fully transcribed verbatim in Arabic and typed using Microsoft Word. Emotions, voice tone, or any changes in participants' behaviours noticed in the videos were added to the observation notes. We used ATLAS.ti, version 7, a software for qualitative data analysis, to support the analysis.

The data analysis was inspired by Giorgi's phenomenological method (10). Each interview was first read completely to gain a sense of the whole description. The interview was then reread from the start to identify key statements about the participants' experiences, constituting "meaning units" expressed in the participants' own everyday language. Once the meaning units were established, transformation of the participants' everyday language was required (13). In this step, the statements of the participants were transformed by two investigators to express the insight contained in them more directly. Then the meaning units of the 50 interviews were combined inferring the general meaning structure of the experience from the transformed meaning units (14).

\section{Ethical considerations}

The study was authorized by the ethics committee of Hôtel-Dieu de France Hospital (CEHDF 1135). Oral and written informed consent was obtained from each participant after being provided with both written and oral information about the aim of the study. A number was randomly assigned to each patient ( $\mathrm{P} 1, \mathrm{P} 2$, etc.) and a concordance table was kept to preserve anonymity.

\section{Results}

\section{Demographics}

A total of 135 patients were contacted, and 50 agreed to be interviewed, of whom 45 were filmed and 5 were audio-recorded. This number of participants was necessary to gain insight into the variety of meanings of the phenomena of living with COPD in Lebanon. The participants lived in different regions of Lebanon: 27 in Mount Lebanon, 21 in Beirut, and 2 in southern Lebanon.

The age of the respondents varied between 50 and 93 years, with a mean of 71.5 (standard deviation, 9) years and a sex ratio of 1.27 male/female ( 28 males and 22 females). The majority of participants had moderate COPD $(40 \%)$, used support from a caregiver (84\%) and were retired (64\%) (Table 1).

\section{Living with chronic obstructive pulmonary disease}

The essence of living with COPD in Lebanon, from the participants' perspective, is to be seen as living in a "lesser world", striving for a breath of life. Living with COPD means living with vulnerability and uncertainty influenced by the body's capacity and the environmental resources that impose the need for support to cope with daily life (Table 2).

\section{Chronic obstructive pulmonary disease: vulnerability and uncertainty}

Participants described living with COPD as being forced into sedentary and solitary lifestyle. The physical impact due to COPD expressed by participants ranged from fatigue and dyspnoea to inactivity and dependence, either because of the inability to move or the oxygen device that impede their movement, resulting in a negative experience. Living with this disease is living with dyspnoea that can worsen at any time. Difficulties in predicting the symptoms of COPD and their impact on daily life limit the participants' ability to plan activities in advance. 


\begin{tabular}{|c|c|c|c|}
\hline \multirow[t]{2}{*}{ Characteristic } & \multicolumn{3}{|c|}{ Frequency } \\
\hline & No. & Patient number & $\%$ \\
\hline \multicolumn{4}{|l|}{ Age (years) } \\
\hline$<60$ & 5 & P8, P26, P27, P28, P34 & 10 \\
\hline $60-69$ & 15 & $\mathrm{P}_{3}, \mathrm{P}_{4}, \mathrm{P}_{6}, \mathrm{P}_{15}, \mathrm{P}_{17}, \mathrm{P}_{18}, \mathrm{P}_{19}, \mathrm{P}_{21}, \mathrm{P}_{24}, \mathrm{P}_{25}, \mathrm{P}_{32}, \mathrm{P}_{36}, \mathrm{P}_{44}, \mathrm{P}_{46}, \mathrm{P}_{4}$ & 30 \\
\hline $70-80$ & 23 & $\begin{array}{l}\mathrm{P}_{1}, \mathrm{P}_{2}, \mathrm{P}_{5}, \mathrm{P}_{7}, \mathrm{P}_{10}, \mathrm{P}_{12}, \mathrm{P}_{13}, \mathrm{P}_{16}, \mathrm{P}_{20}, \mathrm{P}_{22}, \mathrm{P}_{23}, \mathrm{P}_{29}, \mathrm{P}_{30}, \mathrm{P}_{31}, \mathrm{P}_{33}, \mathrm{P}_{35}, \mathrm{P}_{37}, \mathrm{P}_{3} 8, \mathrm{P}_{40}, \mathrm{P}_{41}, \mathrm{P}_{43} \text {, } \\
\mathrm{P}_{48}, \mathrm{P}_{50}\end{array}$ & 46 \\
\hline$>80$ & 7 & $\mathrm{P}_{9}, \mathrm{P}_{11}, \mathrm{P}_{14}, \mathrm{P}_{39}, \mathrm{P}_{42}, \mathrm{P}_{45}, \mathrm{P}_{49}$ & 14 \\
\hline \multicolumn{4}{|l|}{ Sex } \\
\hline Male & 28 & $\begin{array}{l}\mathrm{P}_{1}, \mathrm{P}_{4}, \mathrm{P}_{5}, \mathrm{P}_{6}, \mathrm{P}_{7}, \mathrm{P}_{9}, \mathrm{P}_{13}, \mathrm{P}_{16} . \mathrm{P}_{18}, \mathrm{P}_{19}, \mathrm{P}_{20}, \mathrm{P}_{21}, \mathrm{P}_{22}, \mathrm{P}_{23}, \mathrm{P}_{24}, \mathrm{P}_{26}, \mathrm{P}_{27}, \mathrm{P}_{29}, \mathrm{P}_{30}, \mathrm{P}_{31}, \mathrm{P}_{32} \\
\mathrm{P}_{36}, \mathrm{P}_{37}, \mathrm{P}_{40}, \mathrm{P}_{41}, \mathrm{P}_{42}, \mathrm{P}_{43}, \mathrm{P}_{50}\end{array}$ & 56 \\
\hline Female & 22 & $\begin{array}{l}\mathrm{P}_{2}, \mathrm{P}_{3}, \mathrm{P} 8, \mathrm{P}_{10}, \mathrm{P}_{11}, \mathrm{P}_{12}, \mathrm{P}_{14}, \mathrm{P}_{15}, \mathrm{P}_{17}, \mathrm{P}_{25}, \mathrm{P}_{28}, \mathrm{P}_{33}, \mathrm{P}_{34}, \mathrm{P}_{35}, \mathrm{P}_{3} 8, \mathrm{P}_{39}, \mathrm{P}_{44}, \mathrm{P}_{45}, \mathrm{P}_{46}, \mathrm{P}_{47} \text {, } \\
\mathrm{P}_{48}, \mathrm{P}_{49}\end{array}$ & 44 \\
\hline \multicolumn{4}{|l|}{ Disease severity } \\
\hline Mild & 6 & $\mathrm{P}_{13}, \mathrm{P}_{17}, \mathrm{P} 18, \mathrm{P}_{20}, \mathrm{P}_{22}, \mathrm{P}_{2} 8$ & 12 \\
\hline Moderate & 20 & $\mathrm{P}_{4}, \mathrm{P}_{6}, \mathrm{P}_{12}, \mathrm{P}_{15}, \mathrm{P}_{16}, \mathrm{P}_{19}, \mathrm{P}_{23}, \mathrm{P}_{25}, \mathrm{P}_{26}, \mathrm{P}_{29}, \mathrm{P}_{30}, \mathrm{P}_{31}, \mathrm{P}_{34}, \mathrm{P}_{35}, \mathrm{P}_{3} 6, \mathrm{P}_{3}$, P39, $\mathrm{P}_{44}, \mathrm{P}_{46}, \mathrm{P}_{7}$ & 40 \\
\hline Severe & 10 & $\mathrm{P}_{7}, \mathrm{P}_{9}, \mathrm{P}_{10}, \mathrm{P}_{11}, \mathrm{P}_{27}, \mathrm{P}_{33}, \mathrm{P}_{37}, \mathrm{P}_{40}, \mathrm{P}_{42}, \mathrm{P}_{45}$ & 20 \\
\hline Very severe & 14 & $\mathrm{P}_{1}, \mathrm{P}_{2}, \mathrm{P}_{3}, \mathrm{P}_{5}, \mathrm{P}_{8}, \mathrm{P}_{14}, \mathrm{P}_{21}, \mathrm{P}_{24}, \mathrm{P}_{32}, \mathrm{P}_{41}, \mathrm{P}_{43}, \mathrm{P}_{4} 8, \mathrm{P}_{49}, \mathrm{P}_{50}$ & 28 \\
\hline \multicolumn{4}{|l|}{ Age at diagnosis (years) } \\
\hline$<5$ & 24 & $\begin{array}{l}\mathrm{P}_{1}, \mathrm{P}_{6}, \mathrm{P}_{13}, \mathrm{P}_{14}, \mathrm{P}_{15}, \mathrm{P}_{17}, \mathrm{P}_{18}, \mathrm{P}_{19}, \mathrm{P}_{20}, \mathrm{P}_{25}, \mathrm{P}_{26}, \mathrm{P}_{28}, \mathrm{P}_{30}, \mathrm{P}_{32}, \mathrm{P}_{33}, \mathrm{P}_{34}, \mathrm{P}_{35}, \mathrm{P}_{3} 6, \mathrm{P}_{27}, \mathrm{P}_{2} 8 \\
\mathrm{P} 2 \text {, }\end{array}$ & 48 \\
\hline $5-9$ & 19 & $\mathrm{P}_{2}, \mathrm{P}_{3}, \mathrm{P}_{4}, \mathrm{P}_{5}, \mathrm{P} 8, \mathrm{P}_{9}, \mathrm{P}_{12}, \mathrm{P}_{16}, \mathrm{P}_{24}, \mathrm{P}_{27}, \mathrm{P}_{29}, \mathrm{P}_{31}, \mathrm{P}_{41}, \mathrm{P}_{43}, \mathrm{P}_{45}, \mathrm{P}_{4} 6, \mathrm{P}_{4}, \mathrm{P} 49, \mathrm{P}_{50}$ & 38 \\
\hline$>10$ & 7 & $\mathrm{P}_{7}, \mathrm{P}_{10}, \mathrm{P}_{11}, \mathrm{P}_{21}, \mathrm{P}_{22}, \mathrm{P}_{23}, \mathrm{P}_{42}$ & 14 \\
\hline \multicolumn{4}{|l|}{ Caregiver } \\
\hline Family member & 34 & $\begin{array}{l}\mathrm{P}_{1}, \mathrm{P}_{4}, \mathrm{P}_{6}, \mathrm{P}_{7}, \mathrm{P}_{9}, \mathrm{P}_{11}, \mathrm{P}_{12}, \mathrm{P}_{14}, \mathrm{P}_{16}, \mathrm{P}_{18}, \mathrm{P}_{19}, \mathrm{P}_{20}, \mathrm{P}_{21}, \mathrm{P}_{23}, \mathrm{P}_{24}, \mathrm{P}_{25}, \mathrm{P}_{27}, \mathrm{P}_{29}, \mathrm{P}_{30}, \mathrm{P}_{31}, \mathrm{P}_{32} \\
\mathrm{P}_{33}, \mathrm{P}_{36}, \mathrm{P}_{37}, \mathrm{P}_{39}, \mathrm{P}_{4}, \mathrm{P}_{41}, \mathrm{P}_{4}, \mathrm{P}_{40}\end{array}$ & 68 \\
\hline Non-family member & 8 & $\mathrm{P}_{2}, \mathrm{P}_{3}, \mathrm{P}_{5}, \mathrm{P}_{8}, \mathrm{P}_{10}, \mathrm{P}_{34}, \mathrm{P}_{35}, \mathrm{P}_{3} 8$ & 16 \\
\hline Without help & 8 & $\mathrm{P}_{13}, \mathrm{P}_{15}, \mathrm{P}_{17}, \mathrm{P}_{22}, \mathrm{P}_{26}, \mathrm{P}_{28}, \mathrm{P}_{46}, \mathrm{P}_{47}$ & 16 \\
\hline \multicolumn{4}{|l|}{ Current work } \\
\hline Yes & 15 & $\mathrm{P}_{4}, \mathrm{P} 6, \mathrm{P}_{4}, \mathrm{P}_{18}, \mathrm{P}_{19}, \mathrm{P}_{22}, \mathrm{P}_{26}, \mathrm{P}_{30}, \mathrm{P}_{34}, \mathrm{P}_{36}, \mathrm{P}_{40}, \mathrm{P}_{42}, \mathrm{P}_{46}, \mathrm{P}_{48}, \mathrm{P}_{4}$ & 30 \\
\hline No & 35 & $\begin{array}{l}\mathrm{P}_{1}, \mathrm{P}_{2}, \mathrm{P}_{3}, \mathrm{P}_{5}, \mathrm{P}_{7}, \mathrm{P}_{9}, \mathrm{P}_{10}, \mathrm{P}_{11}, \mathrm{P}_{12}, \mathrm{P}_{13}, \mathrm{P}_{14}, \mathrm{P}_{15}, \mathrm{P}_{16}, \mathrm{P}_{17}, \mathrm{P}_{20}, \mathrm{P}_{21}, \mathrm{P}_{23}, \mathrm{P}_{24}, \mathrm{P}_{25}, \mathrm{P}_{27}, \mathrm{P}_{28} \\
\mathrm{P}_{29}, \mathrm{P}_{31}, \mathrm{P}_{32}, \mathrm{P}_{33}, \mathrm{P}_{35}, \mathrm{P}_{37}, \mathrm{P}_{3}, \mathrm{P}_{39}, \mathrm{P}_{41}, \mathrm{P}_{43}, \mathrm{P}_{44}, \mathrm{P}_{45}, \mathrm{P}_{47}, \mathrm{P}_{50}\end{array}$ & 70 \\
\hline
\end{tabular}

Therefore, they avoid family gatherings and activities which they think they cannot cope with, e.g. walking alone in the garden, which in itself presents a risk of being sedentary. Moreover, they prefer to receive their care at home, either because it is difficult for them to move around or to preserve the same living conditions.

Participants described COPD as an anxiety-provoking disease that invades all aspects of their lives. They live in constant fear; fear of everything new, fear of long journeys, and fear that the disease will have an impact on their professional lives. An older woman described her fear as "suffocating is not funny".

Concerns related to the Lebanese context, such as financial problems and the feeling of insecurity, make the participants to organize their daily lives according to their living context; which oxygen machine to use in case of a power outage; when to leave the house; what to do if the building does not have an elevator; and financial problems that prevent certain participants from visiting their doctors or even adhering to their medications.
Therefore, to save on expensive physiotherapy sessions, participants taught their caregivers how to help them with breathing exercises. Some participants used computerized consultation because of the difficulty in going to meet with their physician physically.

COPD has an impact on participants' lives; it makes them feel resigned to their state of health as they struggle to maintain vital momentum. Some participants reported the impact of the disease on their physical image and some related these difficulties to the cultural context of the country.

\section{Chronic obstructive pulmonary disease: striving for a breath of life}

Some participants tried to continue their lives as normally as possible, taking precautions not to get sick, adhering to the recommendations of the pulmonologist, setting goals so as not to aggravate their symptoms and contacting their pulmonologist regularly. They wanted 
to know more about their illness and some became selfsufficient and active in their own care.

The experiences of participants with their disease was influenced by the support they receive, whether from family or medical personnel. They reported how helpful the motivation provided by their doctor was. For some, it was difficult to maintain compliance and set goals, so they reported their need for information and regular reassuring follow-ups.

Some participants expressed their need for help to quit smoking and remain so, but rejected the idea of attending specialized centres because of their constraining conditions and because they were convinced that quitting is a matter of self-determination.

Monitoring, whether by the doctor or the family, is a key factor that helped participants in dealing with their disease. Participants' families and friends helped them by securing suitable tobacco-free environments and a sense of safety. Participants clearly expressed the benefits of close monitoring to ensure that the right decisions are made, to detect any deterioration in health status or simply to feel that someone is interested in their condition.

\section{Discussion}

Participants in this study were held back by the symptoms of their disease, they struggled with physical movements (e.g. walking and in some cases even speaking), which led to a more sedentary and solitary life than they had previously or wish to have. In line with our findings, previous studies have found that many COPD patients struggle with being held back by the symptoms of their disease and the challenges of breathing, which is associated with social isolation (15-20). Health care staff, particularly nurses, play a major role in managing the health issues of patients with chronic illness $(20,21)$. Nurses should be more aware that the sedentary lifestyle of COPD patients might be by necessity and not by choice, and therefore adopt a sensitive approach. Moreover, nurses are encouraged to develop strategies for patients to maintain physical and social activities and adhere to clinical recommendations.

It is important to recognize that respiratory symptoms are prevalent and distressing in pulmonary disease. All participants described anxiety, fear, panic or distress with shortness of breath with having to stop to get air in. They reported being stigmatized because of their symptoms, and this is consistent with the findings from other studies $(22-25)$. Some even isolated themselves at home to avoid the embarrassment of showing their symptoms in public. From a phenomenological point of view, moving from avoidance to acceptance of one's own body is a crucial shift since the body is understood to be a mode of access to the world (26). From this perspective, it is understandable that the negative feelings due to the symptoms of COPD lead to a distancing from one's own body and certain dimensions of the everyday world. This contributes to the risk of living a sedentary lifestyle and reduced social network, resulting in further deterioration. Thus, it is important to adopt a multidisciplinary approach to addressing the psychosocial needs of COPD patients.

To overcome problems related to the unavailability of the doctor, the difficulty in moving around, long journeys to reach the clinic, or long waiting times at the doctor's clinic, participants used the internet and TV shows to find out more about their disease, which exposed them to wrong information, unsuited to their state of health. Some participants reported the use of self-medication, consistent with other research (27). Even in emergency situations, participants declared the use of prescriptions collected during previous consultations. According to a previous survey, the vast majority of drugs used in self-medication came from a resumption of previously prescribed treatment, while $28 \%$ were purchased on the patient's initiative (28); this could result in inappropriate or ineffective use of medication and consequently an unintentional non-adherence to recommendations. Thus, the importance of patient education cannot be over-emphasized. Moreover, to meet today's demands for accessible and efficient care, it is important to develop new methods, such as eHealth strategies, to facilitate and promote partnership between health professionals and patients (29).

The majority of participants relied on family members to fill the gaps in carrying out tasks they once did alone; this is contrary to findings of other research showing that COPD participants tended to rely primarily on themselves to avoid burdening their relatives and close friends (22). This is explained by social relations and support from family as well as friends which is considered "the axis of Lebanese values, beliefs and culture" (30). The Lebanese population still has relatively strong family networks, and cultural ideals continue to support intergenerational co-residence (31). According to Lebanese cultural norms, older people generally have great expectations of help from their children and family members. Caregivers in this study had no previous knowledge or experience of disease management, decision-making during complications, or interpersonal challenges, which is in line with the findings of other studies that emphasize the importance of involving caregiver in any strategies tailored for COPD patients and as contributors partnering with health care professionals $(32,33)$.

As in many other countries, Lebanon experiences economic inequalities in health; it offers few benefits in terms of welfare, health care and pensions. Economic problems were widely discussed during the interviews because they are barriers to therapeutic adherence and medical consultation. Although other American and British studies also described the financial worries of COPD participants concerning funding their care (34,35), policies to protect older adults in Lebanon are extremely weak in comparison (9). Considering the lack of formal government support, increasing attention by nongovernmental agencies is helping to address unmet needs for health care (9). Therefore, health care 
professionals should help participants to identify available resources that are best for them.

\section{Methodological considerations}

Some authors claim that credibility, authenticity, criticality and integrity remain the main criteria of scientificity in qualitative research (36). Credibility is respected when the research results truly describe the phenomenon. Thus, it was our intention to recruit a large group of participants with diverse socioeconomic characteristics and to conduct interviews beyond data redundancy. Moreover, all prior assumptions of the authors about living with COPD were set aside throughout the process of data collection and analysis.

Authenticity is used to clarify whether the results correspond to the experience as described by each of the participants. Therefore, we read the transcripts of the interviews multiple times; we made audio and video recordings of the interviews and conducted a second visit to validate our interpretation of the transcripts. Audio recordings allowed us to gather information from patients intimidated by the presence of cameras, especially those who thought that the disease had an impact on their physical image.

Criticality refers to the constant critical attitude of the researcher in order to avoid bias. We followed the Giorgi methodological framework (10) throughout data collection and analysis.

Integrity illustrates the researcher's concern to validate his or her interpretations based on the data, therefore we avoided prematurely formulating the essence of the phenomenon by achieving redundancy before ending data collection and making a second visit.
However, the interviews were conducted with patients living in only three governorates of Lebanon: Beirut, Mount Lebanon and South Lebanon. Excluding patients living in other more rural districts may have limited the findings of this study.

\section{Conclusion}

Living with COPD means living with vulnerability and uncertainty influenced by the body's capacities and the economic challenges of a country with limited resources, which imposes on patients a need for support to cope with daily life. Therefore, participants turn to their families in a cultural context where the family continues to be seen as the primary provider of support. The results of our study show that COPD affected three dimensions of participants' lives. These were the educational dimension, where the lack of information was a need and a factor that influenced the COPD patients' experience with their disease; the coordination dimension as patients were obliged to reorganize their lives according to the Lebanese context (financial, social); and the psychosocial dimension given the impact of the disease on social life, professional life, physical image and emotional well-being as expressed by the participants. Therefore, therapeutic education has been recognized as a need for COPD patients in Lebanon. In addition, the development of interventions that include family caregivers and the cooperation of all health professionals is vital. Furthermore, to respond to patients' demands for easy access to care, it is important to develop new methods of facilitating and promoting the partnership between health professionals and patients while preserving patient comfort. Thus governmental and health care efforts are needed to improve the experiences of patients with COPD in Lebanon and to improve their quality of life.

\section{Acknowledgement}

The authors would like to thank the 50 persons who participated in this study for finding the time to share their experiences. We would also like to thank the pulmonologists (Zeina Aoun, Ihab Ibrahim, Georges Dabar, Georges Khayat, Moussa Riachi, Paul Makhlouf, Carlos Njeim, Diana Sassine) who assisted us in the recruitment by providing lists of their patients. The authors would like to also thank Elissa Naim for reviewing the article.

Funding: This work was supported by a grant from the Lebanese University.

Competing interests: None declared.

\section{Vivre avec une bronchopneumopathie obstructive chronique au Liban : une étude phénoménologique \\ Résumé}

Contexte : Le Liban est le pays de la région arabe qui connaît la croissance la plus rapide de sa population de personnes âgées, mais il dispose de peu de ressources sociales pour répondre à leurs besoins. Aucune étude n'a examiné l'expérience des patients atteints de bronchopneumopathie obstructive chronique au Liban.

Objectifs : Examiner les expériences des personnes vivant avec une bronchopneumopathie obstructive chronique au Liban. 
Méthode : À l'aide d'un modèle de recherche phénoménologique descriptive, des entretiens qualitatifs individuels semi-structurés ont été menés auprès de personnes atteintes de bronchopneumopathie obstructive chronique vivant au Liban, entre mai et septembre 2019.

Résultats : Cinquante participants ont accepté d'être interrogés. La majorité étaient des hommes $(56 \%)$ et avaient une bronchopneumopathie obstructive chronique modérée ( $40 \%$ ). L'âge moyen était de 71,5 ans (écart type 9,0). Nous avons constaté que la bronchopneumopathie obstructive chronique a une incidence sur trois aspects de la vie des patients : éducatif, organisationnel et psychosocial.

Conclusion : Les résultats soulignent la nécessité de mettre en place des stratégies multidisciplinaires pour prendre en compte les besoins des personnes atteintes de bronchopneumopathie obstructive chronique au Liban, y compris les personnes chargées de leurs soins. Ces stratégies comprennent l'éducation des patients et la mise au point de nouvelles méthodes pour faciliter et promouvoir la collaboration entre les professionnels de santé, les patients atteints de bronchopneumopathie obstructive chronique et les personnes chargées de leurs soins.

$$
\begin{aligned}
& \text { المصابون بمرض الانسداد الرئوي المزمن في لبنان: دراسة الظواهر }
\end{aligned}
$$

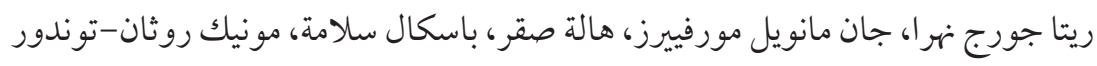

$$
\begin{aligned}
& \text { الخلاصة }
\end{aligned}
$$

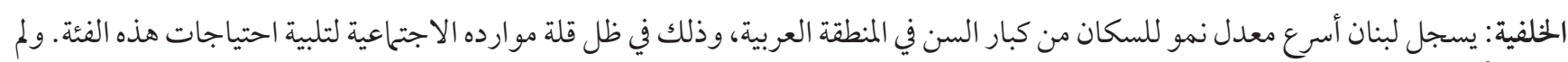

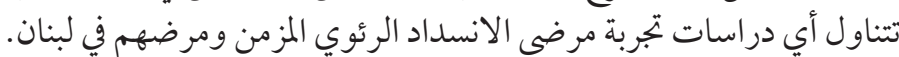

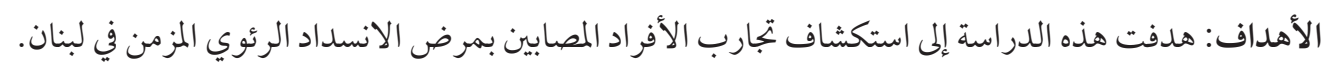

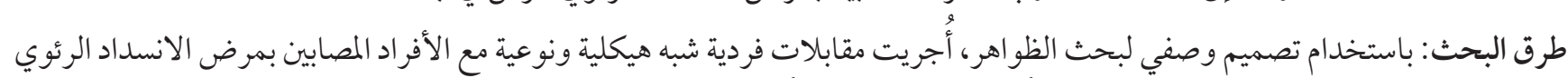

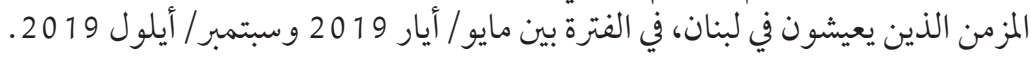

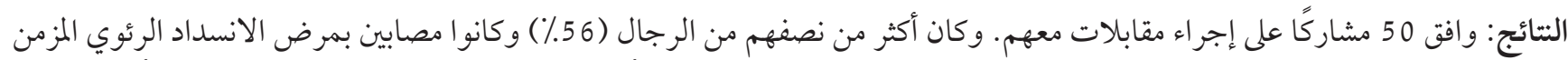

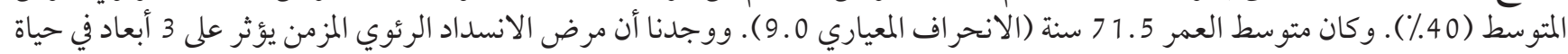
المرضى: التعليمية والتنظيمية وان وانفسية الاجتماعية.

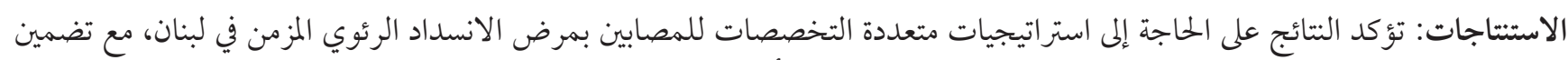

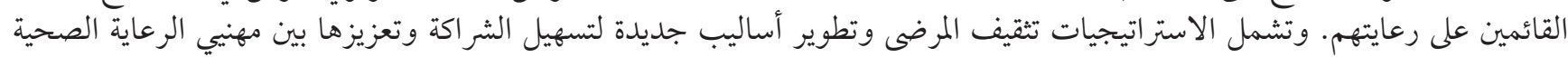
ومرضى الانسداد الرئوي المزمن و القائمين على رعايتهن.

\section{References}

1. Mathers CD, Loncar D. Projections of global mortality and burden of disease from 2002 to 2030. PLoS Med. 2006 Nov;3(11):e442. doi:10.1371/journal.pmed.0030442

2. Lortet-Tieulent J, Soerjomataram I, López-Campos JL, Ancochea J, Coebergh JW, Soriano JB. International trends in chronic obstructive pulmonary disease mortality, 1995-2017. Eur Respir J. 2019 Dec 19;54(6):1901791. doi:10.1183/13993003.01791-2019

3. Waked M, Khayat G, Salameh P. Chronic obstructive pulmonary disease prevalence in Lebanon: a cross- sectional descriptive study. Clin Epidemiol. 2011;3:315-23. doi:10.2147/CLEP.S26350

4. Idrees M, Koniski M-L, Taright S, Shahrour N, Polatli M, Kheder AB, et al. Management of chronic obstructive pulmonary disease in the Middle East and North Africa: Results of the BREATHE study. Respiratory Medicine. 2012 Dec 1;106(Suppl. 2):S33-44. doi:10.1016/So954-6111(12)70013-6

5. Rabe KF, Hurd S, Anzueto A, Barnes PJ, Buist SA, Calverley P, et al. Global strategy for the diagnosis, management, and prevention of chronic obstructive pulmonary disease: GOLD executive summary. Am J Respir Crit Care Med. 2007 Sep 15;176(6):532-55. doi:10.1164/rccm.200703-456SO

6. Cooper CB. Airflow obstruction and exercise. Respiratory Medicine. 2009 Mar 1;103(3):325-34 . doi:10.1016/j.rmed.2008.10.026

7. Jonkman NH, Westland H, Trappenburg JCA, Groenwold RHH, Bischoff EWMA, Bourbeau J, et al. Characteristics of effective self-management interventions in patients with COPD: individual patient data meta-analysis. Eur Respir J. 2016 Jul;48(1):55-68. doi:10.1183/13993003.01860-2015

8. MacNee W. Is Chronic Obstructive Pulmonary Disease an Accelerated Aging Disease? Ann Am Thorac Soc. 2016 Dec;13(Suppl. 5):S429-37. doi:10.1513/AnnalsATS.201602-124AW

9. Abdulrahim S, Ajrouch KJ, Antonucci TC. Aging in Lebanon: Challenges and Opportunities. Gerontologist. 2015 Aug;55(4):511-8. doi:10.1093/geront/gnuo95 
10. Giorgi A. The descriptive phenomenological method in psychology. A modified Husserlian approach. Pittsburgh: Duquesne University Press; 2009.

11. O'Brien BC, Harris IB, Beckman TJ, Reed DA, Cook DA. Standards for Reporting Qualitative Research: A Synthesis of Recommendations. Acad Med. 2014 Sep;89(9):1245-51. doi:10.1097/ACM.0000000000000388

12. Dahlberg K, Dahlberg H, Nystrom M. Reflective lifeworld research, 2nd ed. Lund: Studentlitteratur; 2008.

13. Giorgi A. The theory, practice, and evaluation of the phenomenological method as a qualitative research procedure. J Phenomenolog Psychol. 1997;28(2):235-60.

14. Giorgi A. The descriptive phenomenological psychological method. J Phenomenolog Psychol. 2012;43(1):312.

15. Barnett M. Chronic obstructive pulmonary disease: a phenomenological study of patients' experiences. J Clin Nurs. 2005 Aug;14(7):805-12. doi:10.1111/j.1365-2702.2005.01125.x

16. Ek K, Sahlberg®Blom E, Andershed B, Ternestedt B-M. Struggling to retain living space: patients' stories about living with advanced chronic obstructive pulmonary disease. J Adv Nurs. 2011 Jul;67(7):1480-90. doi:10.1111/j.1365-2648.2010.05604.x

17. Fraser DD, Kee CC, Minick P. Living with chronic obstructive pulmonary disease: insiders' perspectives. J Adv Nurs. 2006 Sep;55(5):550-8. doi:10.1111/j.1365-2648.2006.03946.x

18. Habraken JM, Pols J, Bindels PJ, Willems DL. The silence of patients with end-stage COPD: a qualitative study. Br J Gen Pract. 2008 Dec;58(557):844-9. doi:10.3399/bjgpo8X376186

19. McMillan Boyles C, Hill Bailey P, Mossey S. Chronic Obstructive Pulmonary Disease as Disability: Dilemma Stories. Qual Health Res. 2011 Feb;21(2):187-98. doi:10.1177/1049732310383865

20. Pooler C. Living With Chronic Lower Pulmonary Disease: Disruptions of the Embodied Phenomenological Self. Glob Qual Nurs Res. 2014 Oct 8;1:2333393614548762. doi:10.1177/2333393614548762

21. Amalakuhan B, Adams SG. Improving outcomes in chronic obstructive pulmonary disease: the role of the interprofessional approach. Int J Chron Obstruct Pulmon Dis. 2015 Jun 26;10:1225-32. doi:10.2147/COPD.S71450

22. Ali L, Fors A, Ekman I. Need of support in people with chronic obstructive pulmonary disease. J Clin Nurs. 2018 Mar;27(56):e1089-96. doi:10.1111/jocn.14170

23. Franssen FME, Smid DE, Deeg DJH, Huisman M, Poppelaars J, Wouters EFM, et al. The physical, mental, and social impact of COPD in a population-based sample: results from the Longitudinal Aging Study Amsterdam. NPJ Prim Care Respir Med. 2018 Aug 10;28(1):30. doi:10.1038/s41533-018-0097-3

24. Berger BE, Kapella MC, Larson JL. The Experience of Stigma in Chronic Obstructive Pulmonary Disease. West J Nurs Res. 2011 Nov;33(7):916-32. doi:10.1177/0193945910384602 Rose S, Paul C, Boyes A, Kelly B, Roach D. Stigma-related experiences in non-communicable respiratory diseases: A systematic review. Chron Respir Dis. 2017 Aug 1;14(3):199-216.

25. Merleau-Ponty M. Phenomenology of perception. Trans. Landes DA. London: Routledge; 2013.

26. Williams V, Hardinge M, Ryan S, Farmer A. Patients' experience of identifying and managing exacerbations in COPD: a qualitative study. NPJ Prim Care Respir Med. 2014 Sep 18;24:14062. doi:10.1038/npjpcrm.2014.62

27. Fainzang S. Médicaments et société. Le patient, le médecin et l'ordonnance. Paris: Presses Universitaires de France; 2001 (https:// www.cairn.info/le-patient-le-medecin-et-l-ordonnance--9782130517269.htm, accessed 28 June 2021).

28. Nissen L, Lindhardt T. A qualitative study of COPD-patients' experience of a telemedicine intervention. Int J Med Inform. 2017 Nov;107:11-17. doi:10.1016/j.ijmedinf.2017.08.004

29. Farhood L, Zurayk H, Chaya M, Saadeh F, Meshefedjian G, Sidani T. The impact of war on the physical and mental health of the family: The Lebanese experience. Soc Sci Med. 1993 Jun;36(12):1555-67. doi:10.1016/0277-9536(93)90344-4

30. Abdulrahim S, Ajrouch KJ, Jammal A, Antonucci TC. Survey Methods and Aging Research in an Arab Sociocultural Context-A Case Study from Beirut, Lebanon. J Gerontol B Psychol Sci Soc Sci. 2012 Nov;67(6):775-82. doi:10.1093/geronb/gbso83

31. McCabe MP, Firth L, O'Connor E. A Comparison of Mood and Quality of Life Among People with Progressive Neurological Illnesses and Their Caregivers. J Clin Psychol Med Settings. 2009 Dec;16(4):355-62. doi:10.1007/s10880-009-9168-5

32. Røthing M, Malterud K, Frich JC. Family caregivers' views on coordination of care in Huntington's disease: a qualitative study. Scand J Caring Sci. 2015 Dec;29(4):803-9. doi:10.1111/scs.12212

33. Gardiner C, Gott M, Payne S, Small N, Barnes S, Halpin D, et al. Exploring the care needs of patients with advanced COPD: An overview of the literature. Respir Med. 2010 Feb;104(2):159-65. doi:10.1016/j.rmed.2009.09.007

34. Norweg A, Collins EG. Evidence for cognitive-behavioral strategies improving dyspnea and related distress in COPD. Int J Chron Obstruct Pulmon Dis. 2013;8:439-51. doi:10.2147/COPD.S30145

35. Whittemore R, Chase SK, Mandle CL. Validity in Qualitative Research. Qual Health Res. 2001 Jul 1;11(4):522-37. doi:10.1177/104973201129119299 